\title{
El daño al proyecto de vida: su reconocimiento en la Corte IDH y en la República Dominicana ${ }^{1}$
}

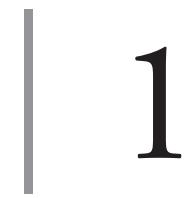

https://doi.org/10.21830/9789585284845.01

Winston M. Ramirez Fondeur ${ }^{2}$

Escuela Militar de Cadetes "General José María Córdova”

\section{Introducción}

Durante los últimos decenios, el derecho de la responsabilidad civil, como disciplina jurídica, ha ido evolucionando a tono con los nuevos paradigmas, reorientando su estudio a nuevos principios y valores, gracias a los fenómenos de constitucionalización del derecho y la sociedad, así como a los procesos de integración de los Estados en este hemisferio y su disposición a adaptar su derecho interno a los convenios y tratados internacionales sobre derechos humanos.

República Dominicana, como otros países de la región, no ha sido la excepción en esta evolución positiva, sino que presenta una nueva etapa como Estado social y democrático de derecho, y un notorio avance en materia de protección y garantía de los derechos fundamentales. La reciente creación del

1 Este capítulo hace parte de los resultados del proyecto de investigación "La legitimidad de las Fuerzas Militares en la geopolítica nacional e internacional de Colombia” del Grupo de Investigación en Ciencias Militares, de la Escuela Militar de Cadetes "General José María Córdova" (ESMIC), registrado con el código COL0082556 de Minciencias. Los puntos de vista y los resultados de este artículo pertenecen al autor y no reflejan necesariamente los de la ESMIC.

2 Licenciado en Derecho, de la Pontificia Universidad Católica Madre y Maestra (PUCMM). Diplome d' Université Droit Comparé et International Des Affaires, Université de Savoie, France. Magíster en Derecho Societario y Comercial (PUCMM). Máster in Bussiness Administration (MBA), University of Phoenix, Estados Unidos de América. Magíster en Derecho Procesal Civil (PUCMM), Diploma sobre Arbitraje Comercial Internacional, en la Facultad de Derecho de la American University de Washington. Desde 2008 ha sido docente en la Escuela de Derecho de la PUCMM. Abogado en ejercicio. Actualmente cursa la Maestría de Derecho Constitucional y Procesal Constitucional (PUCMM). Orcid: https://orcid. org/0000-0002-6979-5935 - Contacto: 19940723@ce.pucmm.edu.do 
Tribunal Constitucional, a partir de la Ley Orgánica N. ${ }^{\circ} 137-11^{3}$ y la proclamación de la Constitución de la República Dominicana, el 26 de enero de 2010, incorporó un amplio catálogo de derechos.

A pesar de los aludidos avances institucionales y democráticos, el ordenamiento jurídico y el sistema de justicia actual de República Dominicana presentan múltiples desafíos, como el actual régimen legal de la responsabilidad civil, el cual no se adapta a la alta proliferación de daños que sufren las personas como consecuencia del desarrollo experimentado por el actual modelo económico y social.

Cuando se evalúan los textos legales que rigen esta materia (aún inertes en el Código Civil), el gran acervo jurisprudencial y los actores mismos del sistema de justicia, se constata un cierto desface con la tendencia moderna, pues el enfoque está dado aún en disciplinar la falta del responsable y no en reparar adecuadamente el daño. No obstante, las últimas decisiones de la Suprema Corte de Justicia permiten armonizar el derecho con esta tendencia.

Cabe entonces preguntarse: ¿Cuál es el real propósito de la responsabilidad civil? ¿Esta se limita a identificar al culpable o responsable de causar un daño y constreñirlo a asumir su responsabilidad o busca la obligatoriedad del resarcimiento adecuado del perjuicio provocado o sobrevenido por ese daño?

En la actualidad, el derecho de la responsabilidad civil exhibe un fundamento y un rol distinto, enfocados hacia la persona afectada, la magnitud del daño sufrido y sus alcances posibles, a fin de obtener una reparación integral $y$, en consecuencia, esta se traduce, de una deuda de responsabilidad, a un crédito de resarcimiento o reparación (Lambert-Faivre, 1992, p. 13). En tal sentido, existe una tendencia moderna en esta materia a centrar la atención en la víctima, no solo desde la óptica in concreto del daño, sino en las secuelas que este pudiese ocasionar en las condiciones propias del afectado, presentes y futuras (Lambert-Faivre, 1992 p. 12).

Es de destacar la importancia de los tratados internacionales, la protección sistemática de los derechos humanos en el hemisferio sur y las decisiones adoptadas por la Corte Interamericana de Derechos Humanos (en adelante, Corte IDH) dentro del marco de la obligación de los Estados miembros de

3 República Dominicana. Ley N. 13711 Orgánica del Tribunal Constitucional y de los Procedimientos Constitucionales. G. O. N. 10622 del 15 de junio de 2011. 
proteger y respetar la integridad física, la libertad y demás derechos humanos ${ }^{4}$, involucrando a todos sus órganos (el ejecutivo, legislativo y judicial) 5 .

El derecho internacional ha reconocido como deber y obligación del Estado que las reparaciones por violación a los derechos humanos aseguren la restitución integral del derecho conculcado, así como del daño material y moral sufrido por la víctima, todo lo cual ha sido desarrollado y ampliado a través de la jurisprudencia.

Con motivo de ello, la Corte IDH ha establecido diversos criterios de reparación, para satisfacer los daños causados por el lucro cesante, el daño emergente y el daño moral, surgiendo así, más recientemente, el concepto del daño al proyecto de vida (Calderón Gamboa, 2005, p. 12). Este último se reconoce como el menoscabo que sufre una persona que ve afectado su plan de vida, con lo cual se afecta su libertad fenoménica — la que tiene cada individuo para decidir cómo situarse ante el mundo y llevar a cabo un proyecto de vida-.

Esta nueva concepción del daño, a la cual se le ha reconocido autonomía conceptual, es una creación doctrinaria, reconocida jurisprudencialmente a partir de una sentencia dictada por la Corte IDH, en ocasión del caso Loaiza Tamayo vs. Perú, siendo este asociado al concepto de realización personal, que a su vez, se sustenta en las opciones que el sujeto puede tener para conducir su vida y alcanzar el destino o plan que se propone (Corte IDH, 1998, \$ 48).

En este sentido, la Corte IDH no solo reconoce la autonomía conceptual del daño al proyecto de vida dentro de la categoría de daños inmateriales, sino que, por medio de sus decisiones adoptadas más recientemente, le ha reconocido autonomía resarcitoria, lo cual genera su cuantificación y la correspondiente disposición de indemnizaciones pecuniarias a favor de las víctimas de tales daños.

4 En el continente americano, a partir de la creación de la Organización de Estados Americanos (OEA) en 1948, se cuenta con la Declaración Americana de Derechos Humanos, y, desde los ańos setenta, existe una Comisión Interamericana de Derechos Humanos. Desde 1979, con la entrada en vigor de la Convención Americana sobre Derechos Humanos, nació la Corte Interamericana de Derechos Humanos. Para una breve explicación sobre esta, véase www.didh.org

5 Conforme a dichos convenios internacionales, los Estados tienen la obligación de cesar los actos que violenten dichos acuerdos y adoptar las medidas para garantizar la no repetición de estos. 
En lo que sigue de esta exposición, abordaremos el concepto del daño al proyecto de vida, su fundamentación jurídica, su reconocimiento y aplicación por la Corte IDH a partir de 1998 y las posibilidades de su resarcimiento. Posteriormente, analizaremos cuál ha sido la experiencia en la República Dominicana, en torno al reconocimiento del daño al proyecto de vida, haciendo acopio del respaldo jurídico desde el punto de vista constitucional y jurisprudencial. De acuerdo con lo anterior, es posible afirmar que se han sentado las bases para la defensa y exaltación de la persona humana y de su libertad más allá de los textos, en concordancia con los nuevos paradigmas y reconociendo el proyecto de vida como su mayor exponente.

\section{Conceptualización del daño al proyecto de vida y su reconocimiento en el ámbito internacional}

La terminología del tema objeto de estudio debe de parecernos bastante común o familiar. El término proyecto viene de proyectar, que se refiere a la intención de hacer algo y realizarlo o al plan que se traza para poder hacer algo. Es la idea de una cosa que se piensa hacer y para la cual se establece un modo determinado y un conjunto de medios necesarios.

La noción del proyecto de vida se basa en los pensamientos de los filósofos de la existencia. Su dimensión filosófica descansa en la libertad del ser humano, ya que es una esencia de su ser. Para que haya un proyecto de vida, el ser humano debe sentirse libre de elegir, planificar y llevar a cabo su plan. De ahí que, cuando se reduce la libertad del ser humano a su mínima expresión, se ve coartada la expectativa para lograr su plan de vida. Como bien sostiene Sartre, "el proyecto libre es fundamental, pues es mi ser; soy en tanto que he de ser yo mismo fuera de mí” (Frankl, 1987).

El proyecto de vida tiene una relación íntima con el ser humano, porque este se proyecta de manera constante hacia el futuro como parte de su esencia y existencia. Para el filósofo austríaco Viktor Frankl, el hombre, en última instancia, es su propio determinante. Este se inventa a sí mismo, concibe su propia esencia, es decir, lo que le da sentido a su existencia: lo él que debería o tendría que ser. Es por todo ello que el proyecto de vida constituye la esencia 
del hombre: "El hombre no puede existir sin proyectar. Este tiene la peculiaridad de que no puede vivir si no mira al futuro: sub especie aeternitatis" (Frankl, 1987, p. 75).

Para Fernández Sessarego (2000), uno de los pioneros en desarrollar el concepto doctrinal del proyecto de vida, "decidir supone elegir un determinado proyecto, descartando al mismo tiempo otros proyectos alternativos que se le presentan al ser humano en un momento dado de su historia personal" (2000, p. 5). Asimismo sostiene que "toda decisión libre significa una valoración". Decidir, por tanto, es valorar para optar por este u otro proyecto alternativo. Entonces, la vida se rige por un constante valorar luego de sopesar opciones.

Finalmente, Fernández Sessarego sostiene que el proyecto de vida reviste tanta importancia para el ser humano como la vida misma, es una razón de ser, de vivir, de tal suerte que, si este proyecto resulta coartado, afecta el valor de la vida. En efecto, este personifica el sentido mismo de la vida, aquello que hace que una persona viva a plenitud, aquello que colma sus sueños, sus aspiraciones. Cada ser humano vive según y para su proyecto existencial. Trata de realizarlo, de concretarlo, de convertirlo en una "manera de vivir, en su cardinal modo de existir” (Fernández Sessarego, 2014, p. 45).

Conforme al concepto desarrollado por dicho jurista, el daño al proyecto de vida es la consecuencia de un daño previo, de carácter psicosomático, de tal magnitud que significa la frustración o menoscabo del proyecto de vida, es decir, el impacto es de tal proporción que sume al sujeto en un vacío existencial. Un daño semejante "incide sobre la libertad del sujeto a realizarse según su propia y libre decisión" y es de tal trascendencia que afecta la manera en que el sujeto ha decidido vivir, frustra su destino y le hace perder el sentido de su existencia. Es, por ello, un daño cierto y continuado, que generalmente acompaña al sujeto durante toda su existencia, en tanto que compromete, de forma radical, su peculiar y única manera de ser.

Para distinguir mejor el daño al proyecto de vida de otros daños no patrimoniales, el ejemplo más claro es expuesto por Fernández Sessarego (1992): la situación de un pianista que sufre un accidente de tránsito y pierde varios dedos de ambas manos. La víctima ha sufrido daños de naturaleza patrimonial, como el dańo emergente (gastos de internamiento, honorarios médicos, medicinas, 
etc.) y el lucro cesante (las sumas de dinero que dejaría de percibir); daños no patrimoniales (lesiones corporales causadas); y un daño a la salud de carácter psicosomático, que compromete el bienestar integral del sujeto damnificado.

Cada uno de estos daños citados deberá ser tenido en cuento y cuantificado por el juzgador. Algunos son, incluso, tarifados. Pero, dentro de esta última categoría, no patrimonial, se le ha causado a la víctima un daño radical, que incide en el sentido mismo de su vida. Su proyecto de vida se ha frustrado, puesto que consistía, única y exclusivamente, en ser pianista. Esto era lo que le daba sentido a su existencia, al punto que, en la vida social, este era identificado como pianista.

Sobre la autonomía conceptual, es de mencionar la decisión adoptada por la Corte IDH en el caso de María Loayza Tamayo vs. Perú, que resulta de capital importancia, porque por vez primera se reconoció la existencia de un grave daño al proyecto de vida. No obstante, la Corte se abstuvo de fijar su cuantificación, puesto que la evolución de la doctrina en ese momento no permitía traducir un reconocimiento en términos económicos. A pesar de esto, se reconoció expresamente su autonomía, con preponderancia de la reparación no económica y no simbólica.

Por su parte, Burgos sostiene que la importancia de dicha sentencia de la Corte radica en el reconocimiento del daño al proyecto de vida, como primer paso en esa dirección y propósito, con lo cual se invita a "repensar todo el capítulo de las reparaciones de violaciones de derechos humanos desde la perspectiva de la integralidad de la persona de la víctima y teniendo presente su realización como ser humano, así como la restauración de su dignidad" (2012, p. 307).

Ciertamente, en la decisión de fondo del caso en cuestión, dictada el 17 de septiembre de 1997, la Corte IDH, considerando los daños sufridos por la víctima reclamante, definió, en el voto mayoritario, el daño al proyecto de vida, en la forma siguiente:

Se trata de una noción que se asocia al concepto de realización personal, el que a su vez se sustenta en las opciones que el sujeto puede tener para conducir su vida y alcanzar el destino que se propone. En rigor, tales opciones son la expresión y garantía de la libertad, pues difícilmente se podría decir que una 
persona es verdaderamente libre, si carece de opciones para encaminar su existencia y llevarla a su natural culminación.

Esas opciones poseen, en sí mismas, un alto valor existencial; por lo tanto, su cancelación o menoscabo implica la reducción objetiva de la libertad y la pérdida de un valor.

No se trata de un resultado seguro, que haya de presentarse necesariamente, sino de una situación probable — no meramente posible — dentro del natural y previsible desenvolvimiento del sujeto, que resulta interrumpido y contrariado por hechos violatorios de sus derechos humanos.

Estos hechos cambian drásticamente el curso de la vida del damnificado, imponiéndole circunstancias nuevas y adversas y modificando sus planes y proyectos, formulados a la luz de las condiciones ordinarias en que se desenvolvía su existencia y de sus propias actitudes para llevarlos a cabo con probabilidades de éxito.

Por esta vía, los hechos violatorios de derechos humanos impiden u obstruyen seriamente la obtención del resultado previsto y esperado en la formulación del proyecto de vida y, en conclusión, alteran de manera sustancial el desarrollo del individuo al que afectan. (Corte IDH, 1998)

Cabe señalar que en dicha sentencia se destaca el voto razonado de dos jueces, Cançado Trindade y Abréu Burelli, quienes consideraron que la decisión de concebir autónomamente un daño al proyecto de vida supone la adopción de un paradigma que trasciende la división tradicional de los daños, focalizada en su patrimonialidad, con lo cual se reconoce la necesidad de reorientar y enriquecer la jurisprudencia internacional en materia de reparaciones.

Conforme al criterio de dichos juristas, Burgos (2012, p. 315) destaca la necesidad de "mutar" el paradigma de apreciación de los daños por violaciones a los derechos humanos, para adoptar un punto de vista en toda su integridad (que es la única manera de sostener, luego, una reparación que presuma de ser íntegra); así como apartarse del paradigma de apreciación de los daños utilizado por el derecho privado (con focalización hacia la patrimonialidad o no de las consecuencias).

En tal sentido, el reconocimiento del daño al proyecto de vida de la víctima, mediante dicha sentencia, no solo tiene como único mérito haber reconocido y adoptado un concepto nuevo y autónomo en materia de daños a las personas, como lo es el daño al proyecto de vida, sino que también repre- 
sentó un primer paso para reorientar el curso de la jurisprudencia internacional en la reparación de daños por violación a los derechos humanos.

En cuanto a la evolución jurisprudencial, vale la pena destacar que, si bien a partir de dicha sentencia — referente obligado en el tema objeto de estudio- el reconocimiento de la autonomía conceptual del daño al proyecto de vida ha sido consolidado, no es posible afirmar lo mismo con relación a su autonomía resarcitoria. Como se pudo apreciar en la solución del caso Loayza Tamayo vs. Perú, no le fue impuesta a dicho Estado una indemnización pecuniaria particular, más bien, el daño al proyecto de vida se consideró mayoritariamente como no resarcible en dinero, a partir de 1998.

El reconocimiento de la autonomía resarcitoria del daño al proyecto de vida tuvo lugar gradualmente, por efecto de una evolución jurisprudencial, en la cual, en una primera etapa, este se consideraba resarcible, no mediante indemnización en sumas de dinero, sino en obligaciones de hacer o en especie, hasta que, a partir del 2011, en el caso Gelman vs. Uruguay (2011), se dio lugar a una marcada tendencia a reconocer la autonomía resarcitoria del daño al proyecto de vida (citado por Burgos, 2012, p. 340). Con este caso se creó una nueva etapa en la jurisprudencia de la Corte IDH en cuanto a su resarcimiento e indemnización pecuniaria.

A modo de ilustración, en el caso Gutiérrez Soler vs. República de Colombia, mediante Sentencia de 12 de septiembre de 2005, la Corte IDH se inclinó hacia el resarcimiento en dinero del daño al proyecto de vida, pero sin concederle autonomía resarcitoria, cuantificándolo al momento de determinar la reparación pertinente por daño inmaterial, dentro de esta categoría genérica. Así se verifica en el párrafo 89 de la citada sentencia, en la que se lee textualmente:

Por las anteriores consideraciones, la Corte reconoce la ocurrencia de un daño al "proyecto de vida" del señor Wilson Gutiérrez Soler, derivado de la violación de sus derechos humanos. Como en otros casos, no obstante, el Tribunal decide no cuantificarlo en términos económicos, ya que la condena que se hace en otros puntos de la presente Sentencia contribuye a compensar al señor Wilson Gutiérrez Soler por sus daños materiales e inmateriales (supra párrs. 76, 78, 84.a y 85.a). La naturaleza compleja e íntegra del daño al "proyecto de vida" exige medidas de satisfacción y garantías de no repetición (infra párrs. 103, 104, 105, 107 y 110) que van más allá de la esfera econó- 
mica. Sin perjuicio de ello, el Tribunal estima que ninguna forma de reparación podría devolverle o proporcionarle las opciones de realización personal de las que se vio injustamente privado el señor Wilson Gutiérrez Soler. (Corte IDH, 2005, p. 413)

Como se puede apreciar en dicha sentencia, la Corte IDH reconoció el daño al proyecto de vida y, si bien señaló que ninguna forma de reparación puede devolver o proporcionar a la víctima las opciones de realización personal que le fueron privadas, admitió, en cambio, la necesidad de su resarcimiento. Decisiones como la antes citada fueron numerosas desde el 2001 al 2005, siguiendo el mismo criterio jurisprudencial, por ejemplo, los casos Bulacio vs. República de Argentina (Corte IDH, 2003a) y Myrna Marck Chang vs. Guatemala (Corte IDH, 2003B).

En cambio, en el caso Gelman vs. Uruguay (2011), la Corte reconoció la comisión de un daño al proyecto de vida y estimó pertinente fijar, como justa compensación, en equidad, por concepto de daños inmateriales, la suma de US\$100000 a favor de la señora María Claudia García de Gelman y US\$80000 a favor de María Macarena Gelman García.

Según Burgos (2012, p. 342), con la adopción de la citada sentencia se puso fin a una etapa evolutiva en cuanto al reconocimiento de la autonomía resarcitoria del daño al proyecto de vida, por lo cual, para la Corte IDH, el daño al proyecto de vida goza de autonomía conceptual irrefutable, de plena autonomía resarcitoria y su resarcimiento puede (y a veces debe) traducirse en términos de indemnización pecuniaria.

\section{Reconocimiento y aplicación en República Dominicana}

Antes de proceder a examinar algunas de las sentencias que han sido dictadas por la Suprema Corte de Justicia de la República Dominicana, en reconocimiento expreso del daño al proyecto de vida, es necesario aclarar que no solo los derechos fundamentales son de interés de la Constitución, sino que lo es también el derecho a la reparación. En razón de esto, es pertinente dedicar algunas líneas a las normas constitucionales que rigen la materia, y, sobre todo, a sus implicaciones insoslayables. 
La Constitución dominicana del 26 de enero de 2010 contempla una serie de disposiciones que otorgan rango constitucional no solo a la obligación del Estado de tutelar la libertad, la salud y la vida de la persona humana, sino a la de reparar el daño o afectación de tales derechos, conforme a la ley y el derecho vigentes.

La mayoría de los ordenamientos jurídicos en nuestro hemisferio consagran los derechos fundamentales del hombre y, muy especialmente, tutelan el derecho a la vida, la libertad y el libre desarrollo de la personalidad. Es decir que se protege la libertad en sí misma y su actuación o expresión fenoménica, cuyo máximo exponente es el proyecto de vida.

Con respecto a esto, la República Dominicana se sitúa en similares estándares de protección constitucional. En efecto, en su título II, sobre "Derechos, garantías y deberes constitucionales", la Constitución de República Dominicana consagra en sus artículos 37, 40 y 43 el derecho a la vida $^{6}$, la dignidad, la libertad ${ }^{7}$ de la persona humana y el libre desarrollo de la personalidad ${ }^{8}$.

Asimismo, merece resaltar que los convenios internacionales en materia derechos humanos gozan de misma jerarquía constitucional en el derecho interno. En tal sentido, el artículo 74, numeral 3, de la Constitución dominicana establece que "los tratados, pactos y convenciones relativos a derechos humanos, suscritos y ratificados por el Estado dominicano, tienen jerarquía constitucional y son de aplicación directa e inmediata por los tribunales y demás órganos del Estado" (Ferrer Mac-Gregor, 2011, p. 547).

En consonancia con lo anterior, la República Dominicana es signataria de la Convención Americana de los Derechos Humanos (CADH), asumida como normativa internacional vinculante, parte integral del sistema intera-

6 "Artículo 37.- Derecho a la vida. El derecho a la vida es inviolable desde la concepción hasta la muerte. No podrá establecerse, pronunciarse ni aplicarse, en ningún caso, la pena de muerte".

7 "Artículo 40.- Derecho a la libertad y seguridad personal. Toda persona tiene derecho a la libertad y seguridad personal. Por lo tanto: 1.- Nadie podrá ser reducido a prisión o cohibido de su libertad sin orden motivada y escrita de juez competente, salvo el caso de flagrante delito; 2.- Toda autoridad que ejecute medidas privativas de libertad está obligada a identificarse...”.

8 "Artículo 43.- Derecho al libre desarrollo de la personalidad. Toda persona tiene derecho al libre desarrollo de su personalidad, sin más limitaciones que las impuestas por el orden jurídico y los derechos de los demás”. 
mericano de protección de los derechos humanos, y, por tanto, del bloque de constitucionalidad, en reconocimiento de la necesidad de dotar a los ciudadanos de mayores garantías para preservar las libertades fundamentales de los seres humanos.

De acuerdo con tales disposiciones de rango constitucional, el Estado dominicano garantiza para toda persona el debido respeto a sus derechos fundamentales, incluyendo el derecho a la vida, a la libertad humana y sus manifestaciones. En consecuencia, dicha tutela estatal alcanza los posibles daños al proyecto de vida, y, por consiguiente, una reparación integral, como se evidencia más adelante.

En cuanto al derecho a la reparación, es de resaltar que la mayoría de las constituciones del hemisferio sur han consagrado expresamente la obligación de reparar ciertos daños a la persona y han extendido esta protección a otros daños de manera implícita.

En tal sentido, en su artículo 44, la Constitución dominicana consagra expresamente el derecho a la reparación de daños a la persona, por violación a la intimidad y al honor personal. Igualmente, el artículo 53 de la carta magna consagra el derecho a la reparación, en caso de daños a la salud de las personas causado por productos o servicios de mala calidad.

En ambos casos, la Constitución dominicana remite a la ley las condiciones bajo las cuales se han de reparar los daños y perjuicios derivados de la violación de los derechos consagrados por los citados artículos 44 y 53 de la Constitución.

Sin duda alguna, la constitucionalización del derecho a la reparación en República Dominicana, tal y como sucede en otros países de tradición romano-germánica, viene a crear un nuevo escenario, un verdadero cambio de perspectiva, tanto para la aprehensión como para la determinación del daño reparable (Burgos, 2012, p. 77), ya que esta supone una serie de transformaciones en materia de responsabilidad de daños, tales como los siguientes:

a) La constitucionalización del derecho a la reparación conlleva la inconstitucionalidad de toda norma tendente a desconocer o dejar de lado tales o cuales daños con "relación causal adecuada". 
b) El llamado derecho de daños deja de ser una cuestión de mero interés privado, cobrando entonces un marcado interés público.

c) El respeto a la integridad de las personas, su resarcimiento y la sanción a los responsables devienen en una cuestión de interés estatal, lo cual era antes relegado al ámbito privado, es decir, a las anticuadas reglas que sobre la materia prevé nuestro Código Civil. (Burgos, 2012)

Por tales razones, la responsabilidad civil experimenta una creciente objetivación y socialización, más dedicada a pensar en el estado de las personas después de la ocurrencia de un perjuicio, sea este de naturaleza patrimonial o no patrimonial. Con ella, no solo se persigue reparar, sino precaver, remediar o minimizar el daño; y, si este se produce, busca su resarcimiento de manera integral, independientemente de su naturaleza moral o patrimonial.

$\mathrm{Al}$ respecto, cabe señalar que, durante mucho tiempo, fue objeto de discusión la reparación del daño moral, ya que este se consideraba como no susceptible de una valoración pecuniaria, cuya pretensión de resarcimiento era inmoral, pues no se podía negociar con el dolor humano. Felizmente esa discusión quedó atrás por las mismas razones mencionadas más arriba, y las decisiones de la Suprema Corte de Justicia citadas así lo manifiestan.

En ese mismo sentido, Subero-Isa afirma que el concepto de daño moral y su reparación

ha venido evolucionando de tal manera, que en el caso de nuestro país el asunto no solamente tiene el respaldo de una consolidada jurisprudencia y consagración legislativa, sino que en la actualidad tiene un ribete constitucional en aspectos tan importantes como los derechos fundamentales, dentro de los cuales se encuentran, según disposiciones expresas del artículo 44 de la Constitución, el honor, el buen nombre. (2018, p. 605)

Por otra parte, es preciso destacar que el derecho a la reparación, si bien ha sido elevado al rango constitucional, no es absoluto sino relativo, sobre todo, cuando en una situación concreta choca con otro derecho fundamental, ocasión en la cual uno de ellos deberá ceder frente al otro.

Como veremos enseguida, la Suprema Corte de Justicia en diversas oportunidades ha reconocido el daño al proyecto de vida, así como la facultad del juez de fondo de apreciar la magnitud del daño y establecer una indemniza- 
ción pecuniaria, pero siempre dentro del respeto de los derechos fundamentales, tales como la razonabilidad y la proporcionalidad de la indemnización frente al daño sufrido.

En efecto, mediante una sentencia dictada el 02 de julio de 2014 por la Tercera Sala de la Suprema Corte de Justicia de la República Dominicana, con ocasión de lesiones graves sufridas por un trabajador que perdió una pierna a causa de un accidente laboral, esta reconoció la ocurrencia de un daño cierto, directo y personal en la vida del trabajador afectado, e incluso consideró que el perjuicio sufrido afectaba "en forma sensible" el proyecto de vida del trabajador y su desarrollo laboral. En tal sentido, dicha Corte estableció lo siguiente:

Considerando, que al no cumplir con un deber de seguridad, relativo a las obligaciones inherentes a los deberes propios de la ejecución del contrato de trabajo, ocasionando un daño cierto, directo y personal en la vida misma del trabajador afectado, realizando una evaluación del daño, lo cual es propio de los jueces del fondo, y no entra en la esfera de la Corte de Casación, salvo un estimado irrazonable del perjuicio causado, sin que exista evidencia al respecto, tomando en cuenta que el perjuicio causado afectará en forma sensible el proyecto de vida del trabajador recurrido y su desarrollo laboral, en consecuencia, dichos medios en ese aspecto carecen de base legal, deben ser desestimados y rechazado el presente recurso. (Énfasis ańadido) (Suprema Corte de Justicia, 2014a)

Es de destacar, en este caso, el reconocimiento expreso de la Alta Corte del carácter futuro atribuido al daño al proyecto de vida, es decir, su proyección en el tiempo, que es una de las características que definen este tipo de daños en expresión de su autonomía, como se reconoció anteriormente.

En otra decisión, muy próxima a la anterior, dictada también por la Tercera Sala de la Suprema Corte de Justicia, el 16 de julio de 2014, con ocasión de una demanda en daños y perjuicios a raíz de un accidente laboral, la Alta Corte reconoció y conceptualizó nuevamente el daño al proyecto de vida, resaltando ahora nuevos elementos que lo componen, así como sus alcances. $\mathrm{Al}$ respecto, destacó lo siguiente:

Considerando, que en el caso de que se trata hay un perjuicio, cierto, directo, actual y personal relacionado con el recurrido, que ha de gravitar en su perspectiva de vida, en su proyecto de vida, en su parte afectiva, su relación laboral futura, sus posibilidades y la calidad misma de su vida personal, que ha 
quedado seriamente perjudicada por el daño ocasionado. (Énfasis añadido) (Suprema Corte de Justicia, 2014b)

Merece aquí destacar, en la apreciación del daño, el modo en que la Corte se detiene y concentra su atención en la víctima como persona, valora su dimensión individual y social. De esta forma proyecta hacia el futuro las consecuencias del perjuicio sufrido y reconoce el proyecto de vida como componente de la vida misma (la parte afectiva, la calidad de su vida personal y su relación laboral futura, todo ello trastocado por el daño causado).

Reviste suma relevancia esta otra sentencia dictada por las Salas Reunidas de la Suprema Corte de Justicia, dictada el 28 de agosto de 2013. En ella, la Alta Corte no dejó dudas en cuanto al reconocimiento del daño al proyecto de vida, tanto respecto a su autonomía conceptual como resarcitoria, al decidir casar una sentencia dictada por una Corte de Trabajo del Distrito Nacional, que fijó una indemnización de RD\$1 50000.00 (aprox. US\$30000.00), por daños ocurridos a causa de un accidente laboral que provocó la incapacidad permanente del trabajador. En dicha sentencia, no obstante, la Corte estimó irrazonable el monto de la indemnización, por no haber tomado en cuenta otros daños materiales, así como el daño al proyecto de vida. Al respecto, estableció lo siguiente:

Considerando: que igualmente, el recurrente, con la pérdida futura de sus relaciones de trabajo, que eran las de una persona con su nivel de preparación y especialización en "finanzas, impuestos, contabilidad y auditoría"; sufrió un daño a su proyecto de vida "impidiendo la realización de desarrollo personal y vocacional en condiciones normales y causaron daños irreparables a su vida y a la vida de sus familiares, obligándolo a realizar esfuerzos en condiciones de penuria económica y quebranto físico y psicológico"; daños que deben ser reparados. (Suprema Corte de Justicia, 2013)

En este caso particular, la sentencia dictada constituye un verdadero precedente, de singular relevancia en la materia, ya que reconoció el daño al proyecto de vida para el profesional que vio frustrado su plan de vida, al ser privado de desarrollar sus competencias como profesional de las finanzas en auditoría y contabilidad. Lo cual lo afectó también con la pérdida de sus relaciones futuras y la realización de sus expectativas como parte de su realización 
personal. Por ello, la Corte estableció y reconoció expresamente la obligación de reparar dichos daños.

No es posible concluir el presente trabajo, sin antes advertir que, si bien - conforme a tales precedentes - toda víctima de un daño personal, incluyendo el daño al proyecto de vida, tiene derecho a una reparación integral, esto no debe ser confundido bajo el entendido de que se cumple con la obligación de reparar el daño al fijar como indemnización pecuniaria un valor estimativo. $\mathrm{Al}$ respecto, cabe aclarar que cada caso debe ser valorado concretamente y no de manera abstracta.

En ese sentido, se juzgó que

el perjuicio que sufre la víctima debe ser apreciado in concreto y no abstracto. La causa eficiente del daño sufrido por la víctima no se encuentra en sus predisposiciones, sino en la falta imputable al demandando. La víctima es acreedora de una reparación íntegra. (Subero-Isa, 2018, p. 662)

Asimismo, una indemnización para el proyecto de vida, fijada sin el debido soporte o justificación de su cuantificación, que no cumpla con los deberes de razonabilidad y proporcionalidad, afectará la validez de la sentencia, pudiendo ser casada por falta de motivación. Es preciso que las sumas acordadas a título de indemnización se ajusten al daño sufrido. Sobre la razonabilidad a la cual debe ajustarse toda indemnización, el Tribunal Constitucional de la República Dominicana, en la sentencia TC/150/17 dispuso lo siguiente:

Es así que la argumentación de la Primera Sala de la Suprema Corte de Justicia descansa en la apreciación genérica de los daños y perjuicios que realizó el tribunal inferior; sin embargo, al ponderar el monto de la indemnización impuesta, sus argumentos se apartan de los parámetros de razonabilidad que deben existir entre los daños y perjuicios experimentados, las pérdidas sufridas y las ganancias a las que hubiese sido privado el acreedor; criterios que hubiesen permitido una evaluación objetiva del aspecto controvertido como lo había hecho la misma sala en otras ocasiones. (República Dominicana Tribunal Constitucional, 2017)

En tal sentido, la doctrina sostiene que la acción de responsabilidad civil no persigue un enriquecimiento por parte de quien ha sufrido el daño, sino 
una reparación integral, tanto en el lucro cesante como en el lucro emergente. En ese mismo orden de ideas, se juzgó que

cuando hay varios demandantes en la misma calidad, es deber de los jueces del fondo, en interés de una buena administración de justicia, ponderar en cada caso el grado de perjuicio sufrido por cada uno de ellos, y dar los motivos pertinentes, a fin de que las indemnizaciones correspondan razonablemente al perjuicio que cada uno ha sufrido. (Subero-Isa, 2018, p. 774)

\section{Conclusiones}

El concepto del daño al proyecto de vida goza de autonomía conceptual y resarcitoria por haber sido expresamente reconocido en reiteradas ocasiones, tanto en el ámbito internacional como en la República Dominicana.

Como es natural, cada elemento innovador toma su tiempo para calar en un contexto social y jurídico, sobre todo, en cuanto al aspecto de la cuantificación del daño y su resarcimiento mediante una indemnización pecuniaria, debido, justamente, a la naturaleza inmaterial del daño a reparar. No obstante, tal y como se ha evidenciado, es mucho lo que se ha avanzado en esta materia, pero hay aún mucho camino por recorrer.

Las decisiones emitidas por la Suprema Corte de Justicia en lo tocante al reconocimiento de la autonomía conceptual y resarcitoria del daño al proyecto de vida - en especial, los razonamientos que fueron determinantes para su decisión, transcritos más arriba - constituyen verdaderos precedentes vinculantes para dicha Alta Corte. Esto, sin duda, resulta muy positivo en mérito a la justicia predecible, la igualdad y la seguridad jurídica que merecen todos los ciudadanos.

\section{Referencias}

Burgos, O. (2012). Daños al proyecto de vida. Editora Astrea.

Calderón Gamboa, J. (2005). Reparación del daño al Proyecto de Vida por violaciones a derechos humanos. Editorial Porrúa.

Constitución de la República Dominicana. (2010). Gaceta Oficial No. 10561.

Fernández Sessarego, C. (1992). ¿Existe un daño al proyecto de vida? Revista Persona. http://www. revistapersona.com.ar/Persona11/11Sessarego.htm 
Fernández Sessarego, C. (2000). Daño al proyecto de vida. Revista Jurídica de la Universidad de la Universidad Interamericana de Puerto Rico, 34(3).

Fernández Sessarego, C. (2014). Deslinde conceptual entre daño a la persona, daño al proyecto de vida y daño moral. Revista de Responsabilidad Civil y Seguros, 16 (5), 5-77.

Ferrer Mac-Gregor, E. (2011). Interpretación conforme y control difuso de convencionalidad: el nuevo paradigma para el juez mexicano. Estudios Constitucionales, 9(2), 531-622.

Frankl, V. (1987). El hombre es busca de sentido. Editorial Herder.

Lambert-Faivre, Y. (1992). La evolución de la responsabilidad civil; de una deuda de responsabilidad a un crédito de indemnización. Editora La Ley.

Subero-Isa, J. A. (2018). Tratado práctico de responsabilidad civil dominicana (7.a Ed). Editora Corripio.

\section{Sentencias}

Corte Interamericana de Derechos Humanos. (1998). Caso Loayza Tamayo vs. Perú. Reparaciones y costas. Sentencia de 27 de noviembre de 1998. Serie C No. 42, párr. 48.

Corte Interamericana de Derechos Humanos. (2003a). Caso Bulacio vs. Argentina. Sentencia de Fondo, Reparaciones y Costas.

Corte Interamericana de Derechos Humanos. (2003b). Caso Myrna Mack Chang vs. Guatemala. Sentencia de Fondo, Reparaciones y Costas.

Corte Interamericana de Derechos Humanos. (2005). Caso Wilson Gutiérrez Soler vs. República de Colombia. Fondo, Reparaciones y Costas. Sentencia del 12 de septiembre de 2005.

Corte Interamericana de Derechos Humanos. (2011). Caso Gelman vs. Uruguay. Sentencia de Fondo, Reparaciones y Costas.

República Dominicana - Tribunal Constitucional. (2011). Ley N.o 137-11 Orgánica del Tribunal Constitucional y de los procedimientos constitucionales. G. O. No. 10622 del 15 de junio de 2011.

República Dominicana - Tribunal Constitucional. (2013). Sentencia TC/0094 del 4 de junio de 2013.

República Dominicana - Tribunal Constitucional. (2017). Sentencia del 5 de abril TC 0150 de 2017.

Suprema Corte de Justicia. (2014a). 3. a Sala. Sentencia N. o 354, 2 de julio de 2014.

Suprema Corte de Justicia. (2004b). 3. a Sala. Sentencia No. 376, 16 de julio de 2014.

Suprema Corte de Justicia. (2013). Salas Reunidas. Sentencia del 28 de agosto de 2013. B. J. N. ${ }^{\circ} 1233$. 